\title{
Monitoring Patient/Ventilator Interactions: Manufacturer's Perspective
}

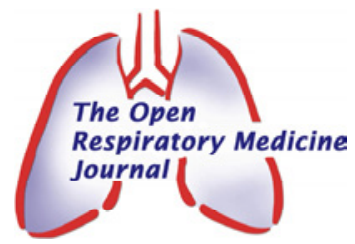

\author{
Gerard Evers* and Carl Van Loey
}

Breas Medical AB, Företagsvägen 1, SE-435 33 Mölnlycke, Sweden

\begin{abstract}
The introduction of reduced and more powerful electronics has allowed the transition of medical equipment such as respiratory support devices from the hospital to the patient's home environment. Even if this move could be beneficial for the patient, the clinician ends up in a delicate situation where little or no direct supervision is possible on the delivered treatment.

Progress in technologies led to an improved handling of patient-device interaction: manufacturers are promoting new or improved ventilation modes or cycling techniques for better patient-ventilator coupling. Even though these ventilation modes have become more responsive to patient efforts, adversely they might lead to events such as false triggering, autotriggering, delayed triggering.

In addition, manufacturers are developing tools to enhance the follow-up, remotely or offline, of the treatment by using embedded memory in the respiratory devices. This logging might be beneficial for the caregiver to review and document the treatment and tune the settings to the patient's need and comfort. Also, remote telemedicine has been raised as a potential solution for many years without yet overall acceptance due to legal, technical and ethical problems.

Benefits of new technologies in respiratory support devices give the technical foundation for the transition from hospital to home and reducing patient/ventilator asynchronies. Healthcare infrastructure has to follow this trend in terms of cost savings versus hospital stays.
\end{abstract}

Keywords: Non-invasive ventilation, home care, patient-ventilator interactions, technology.

\section{MECHANICAL VENTILATION: FROM HOSPITAL TO HOME}

The main objectives for mechanically ventilating a patient are to improve oxygenation, to increase or maintain minute ventilation, to help $\mathrm{CO}_{2}$ clearance, yet by decreasing work of breathing and protecting the airways.

Mechanical ventilators should be adjusted to influence the breathing rate and tidal volume by taking into account patient's physiology and interfaces' dead space.

In the Intensive Care Unit, common Indications for ventilation were reviewed by an international group in 2000 [1],

$\begin{array}{lll}\text { - } & \text { Hypoxemic respiratory failure } & 66 \% \\ \text { - } & \text { Acute exacerbation of COPD } & 13 \% \\ \text { - } & \text { Neuromuscular disorders } & 10 \% \\ \text { - } & \text { Coma } & 10 \%\end{array}$

There is a trend changing towards Non-Invasive Ventilation (NIV) [2-4], especially in the intermediate care units [5] and even more in the home environment [6]. This trend is described in the European survey of 2002: with improving patient status from the Intensive Care Unit to the Respiratory Intermediate Care Unit and the finally the Respiratory Monitoring Unit, more NIV is used [5].

\footnotetext{
*Address correspondence to this author at the Breas Medical AB, Företagsvägen 1, SE-435 33 Mölnlycke, Sweden;

E-mail: gerard.evers@breas.com
}

Even if this epidemiology study mainly considers intermediate care units and not home care, home-care environment as place of care has quickly moved towards NonInvasive Ventilation use [7-9].

The epidemiology of home mechanical ventilation was described in the EuroVent study [8]. This study reviewed the usage of home mechanical ventilation in 329 centres in 16 European countries including more than 16509 patients. The authors concluded wide variations in experience and care provision infrastructures between countries (Fig. 1).

After weaning from invasive ventilatory support and if the patient still requires additional support, long-term home non-invasive ventilation is a key choice for treating hypercapnic chronic respiratory failure patients in absence of socio-economic or medical constraints [10]. Clini and colleagues reviewed data from Italy comparing home NIV (with oxygen) with the cost care of oxygen alone. Hospital related costs were lower in the NIV group [11-13].

Using NIV in the home puts more stress on finding the appropriate settings for the patient on a specific ventilator. Successful ventilation does depend on reduces patient ventilator asynchronies. Asynchronies or more generally patient/ventilator respiratory disturbances may occur and may contribute to failure or discomfort.

\section{PATIENT VENTILATOR INTERACTIONS}

Guo and colleagues identified the patient/ventilator respiratory disturbances to be relatively frequent [14]. They de- 
scribed 4 types of respiratory events versus normal synchronous respiration on a ventilator (Fig. 2):

1. patient/ventilator desynchronization (Fig. 3),

2. periodic breathing (Fig. 5),

3. autotriggering (Fig. 4), and

4. apnea-hypopneas.

(A)

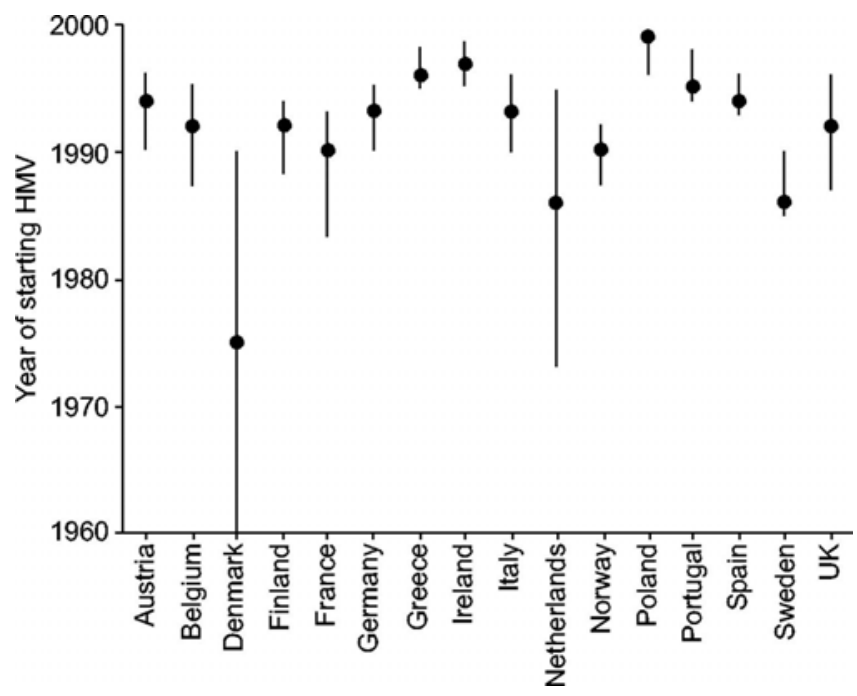

(B)

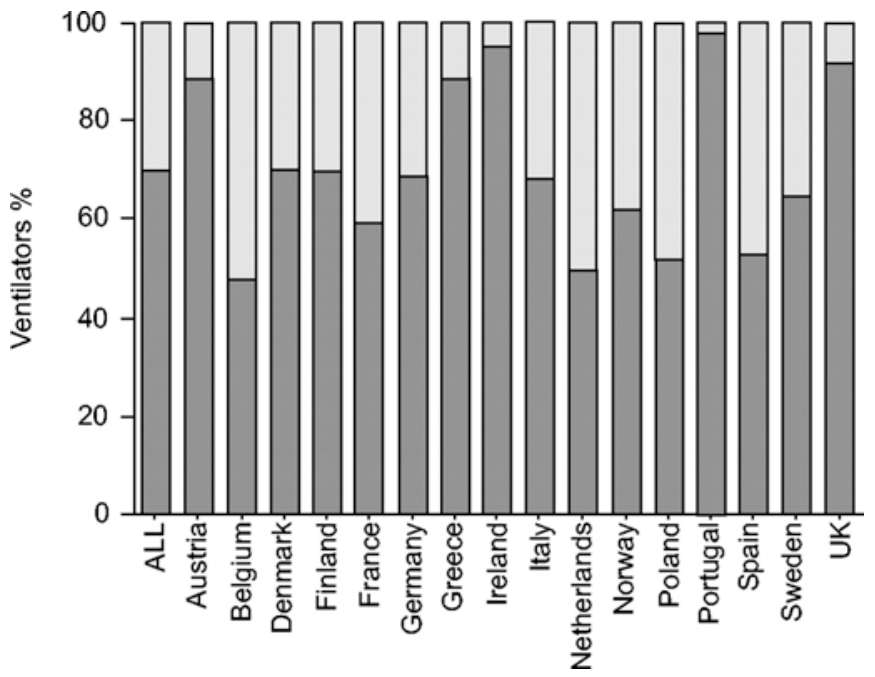

Fig. (1). (A) Median year of starting home mechanical ventilation; (B) Percentage of ventilator type (black: pressure; grey: volume) [8].

Based on various publications, the percentage of asynchrony affects more than 1 out of 4 patients $[15,16]$. The patient ventilator disturbances originate in various sources, including but not limited to bad ventilator performance, inadequate settings and non-intentional leaks. The nonintentional leaks are mostly due to bad mask fitting and have a deleterious effect on ventilator performance [17-23]. The choice of interface is critical to reduce the leaks and assure good ventilation [24]. Meyer et al. wrote about air leaks reducing sleep quality under non-invasive ventilation [25], but specifically the patient ventilator asynchrony that was caused by leaks was not considered. In recent times, patient ventilator asynchrony is being published as having a negative effect on sleep quality for patients using non-invasive ventilation $[26,27]$.

Manufacturers and clinical or university centres are performing studies to compare or to test ventilators in different conditions and thereby to assess in which conditions patient ventilator disordered breathings occurs.

Bench evaluations of mechanical ventilators are a comfortable way of assessing performance of devices in terms of triggering, cycling, monitoring and leakage behaviour [22, 28-36]. Indeed, technology also brought new developments in the bench design.

However, there are both many patient-specific criteria as well a variety of pathologies that makes this task selflimiting, as can be drawn from the bench evaluation designed for paediatric evaluation by the team of Fauroux [28]. Despite this limitation, bench testing allows repetitive evaluations under similar conditions which is not possible on patients. Indeed, comparison of ventilators on patients demands for a large population to be included with common pathology features to yield a statistically significant analysis else outcomes might be non-significant [37].

As written by Stroetz in 1998, "Practitioners willing to make the effort to interpret patient-ventilator interactions will find it difficult to manage ventilator-dependent patients without feedback from waveform analysis in the future"[38].

This was illustrated by example in a case report by Haynes [39]: by using the waveform display on a Pressure Support ventilator, he was able to detect asynchrony and manipulate inspiratory risetime and breath-termination criteria to improve the patient ventilator synchrony.

Even though use of waveforms to reduce patient ventilator respiratory disturbance has become common in the Intensive Care setting [40-43] and sub-acute/monitoring centres, waveforms could sometimes be difficult to interpret for clinicians not routinely using them. Some computerized algorithms exist for the intensive care setting where patients are deemed more under control [44-46]. Alternative automated methods are being developed specifically for non-invasive ventilation. As an example a, entropy based analysis developed in Rouen [47-49] or an algorithm validated in Nava's team [16].

- The entropy based system is using a novel algorithm calculating phase portraits and entropy (mostly used in chaos techniques). It looks at the variability of ventilation and triggering efforts. This method is post-hoc by design but could still yield very useful information for the caregiver to adjust the settings (Fig. 6).

- Another algorithm detects ineffective triggering as perturbations in the expiratory flow unaccompanied by a mechanical breath (Fig. 7). This real-time algorithm designed to be embedded in a ventilator yields a sensitivity of $91 \%$ and a specificity of $97 \%$ according to the authors but on a low number of patients and events, respectively 20 and $159.5 \pm 87.7$ breaths per patients. 

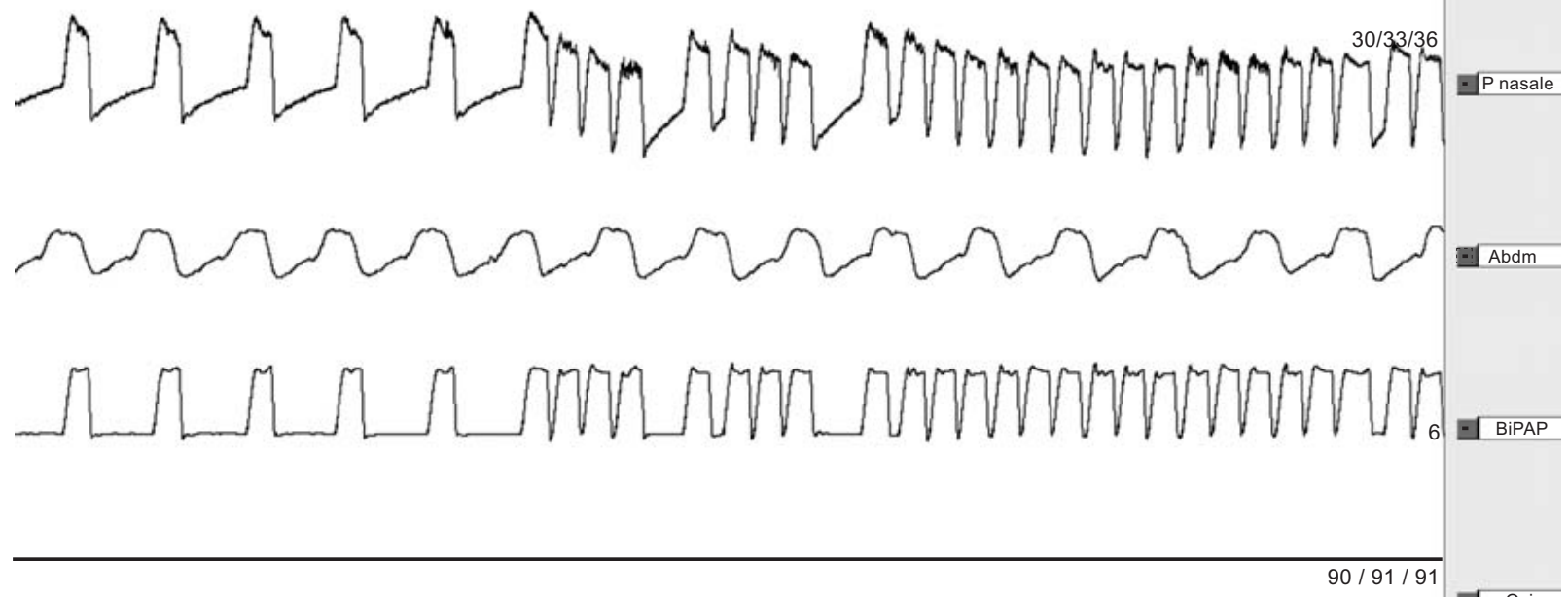

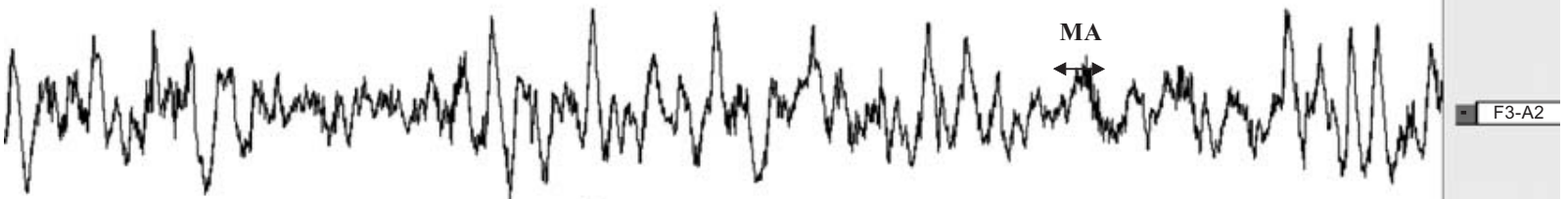

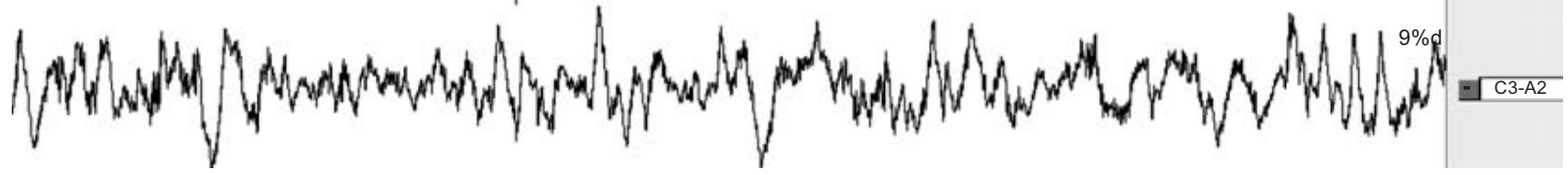

Fig. (2). Polysomnography recording (2min) of a subject with normal ventilation under NPPV during slow-wave sleep [14].

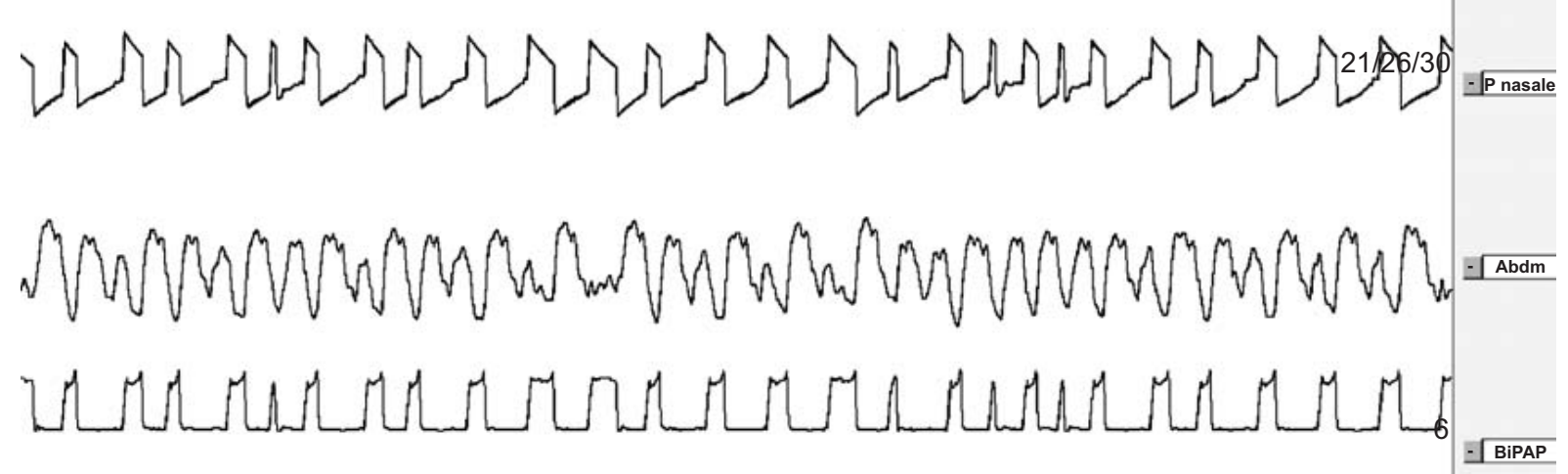

$86 / 88 / 89$

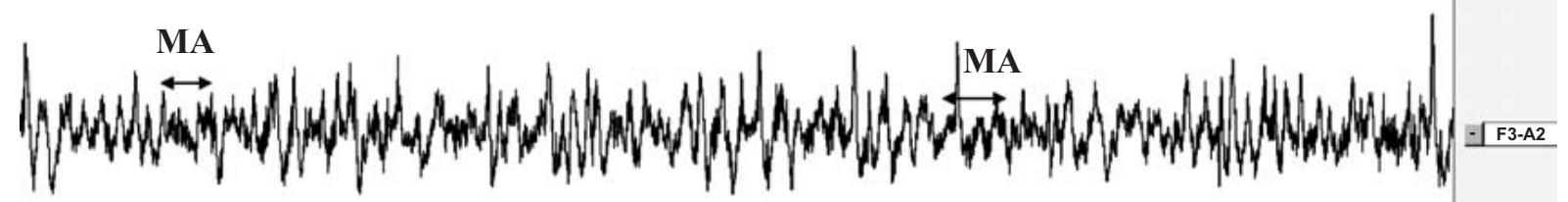

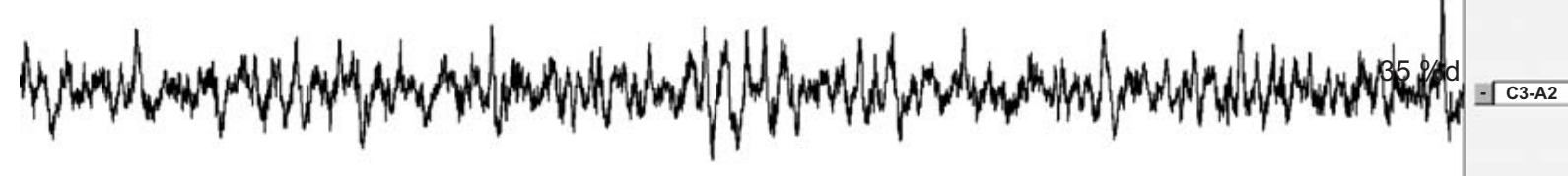

Fig. (3). Polysomnography recording (2 min) of asynchrony in slow wave sleep with micro-arousals [14]. 

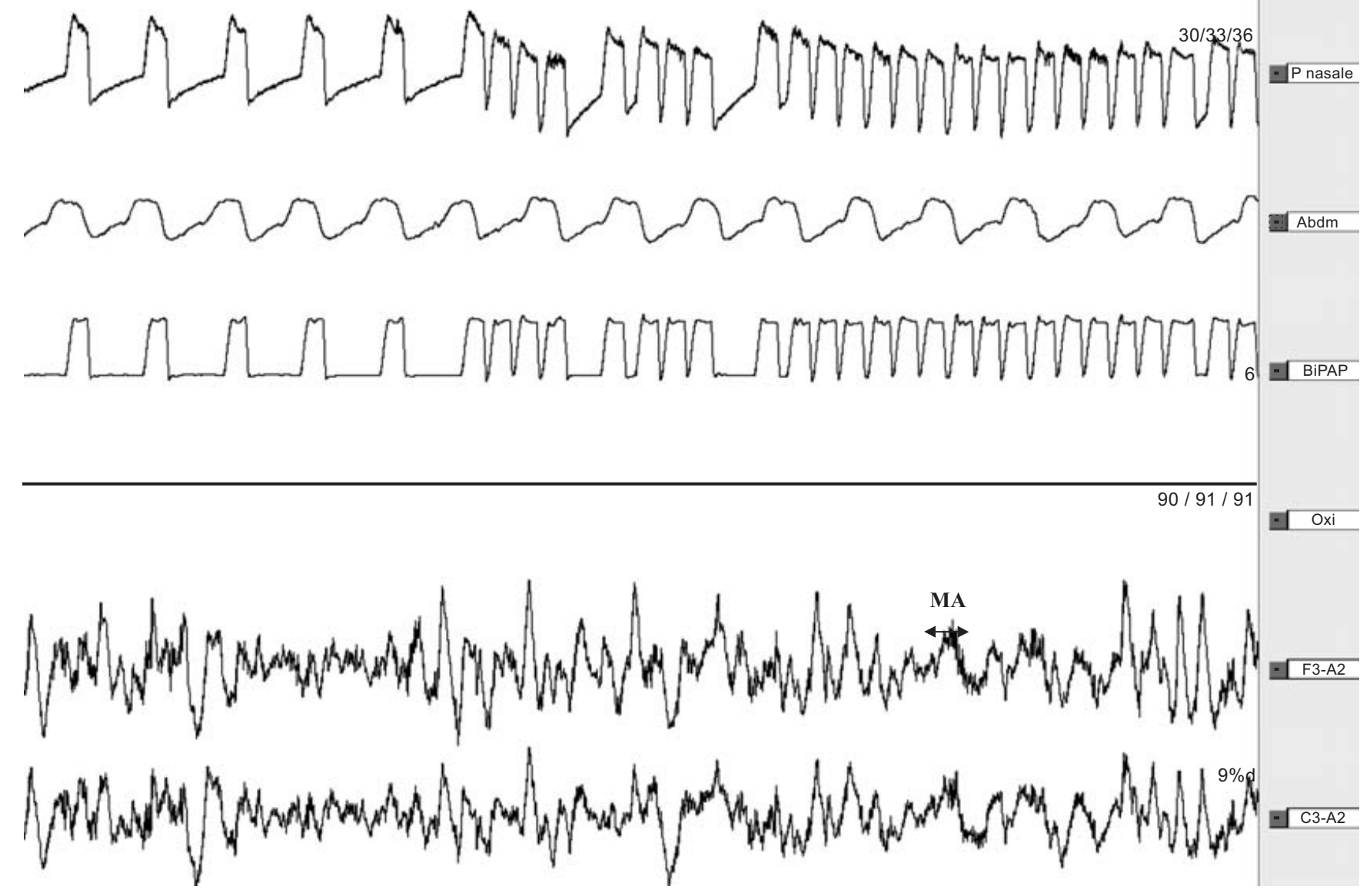

Fig. (4). Polysomnography recording (2min) with auto-triggering during slow wave sleep, inducing microarousals [14].

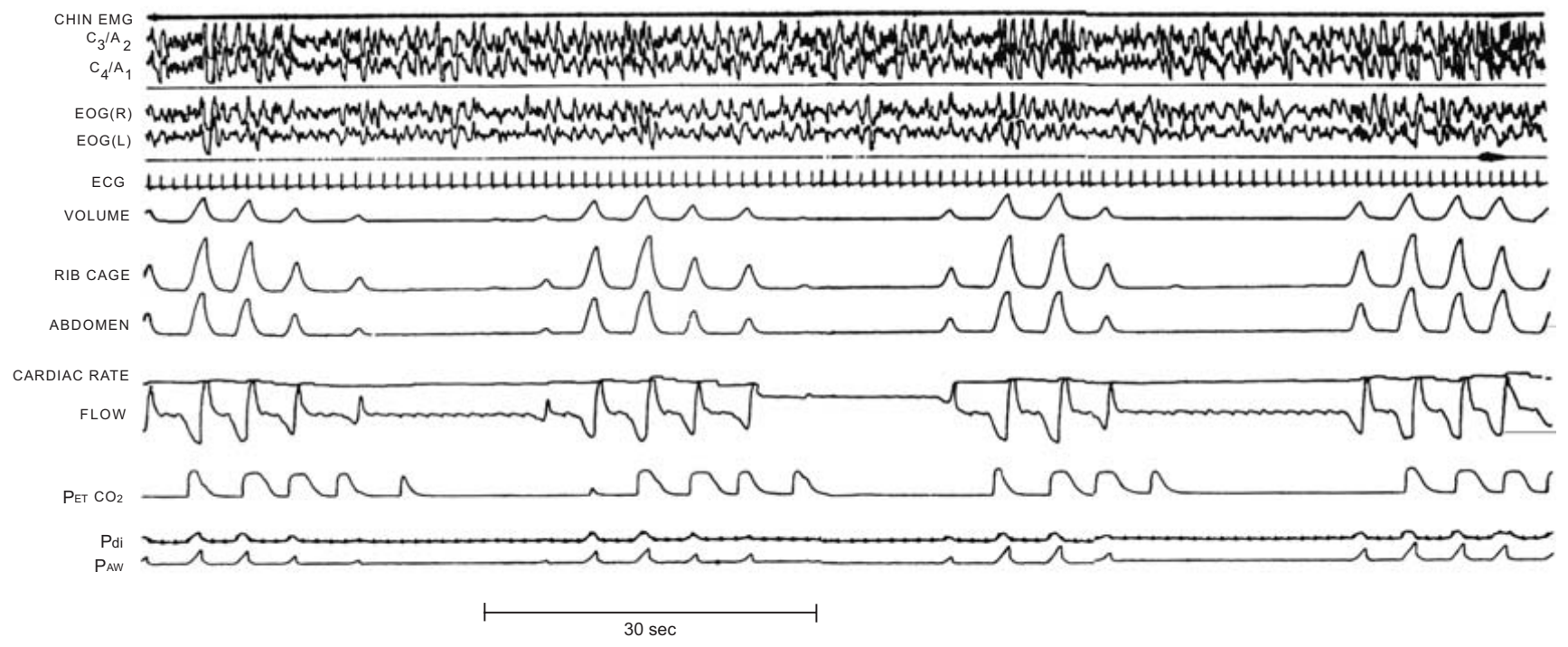

Fig. (5). Polysomnography recording showing Periodic Breathing with repetitive central apnoeas [38].

Using waveforms and advanced non-embedded asynchrony detection algorithms, is more unlikely to be done in the home environment for the simple reason that the clinician does not have access to all patient's vital signs [50]. Moni- toring patients' ventilation implies indeed questioning, examining and monitoring vital signs in addition to looking at the synchronicity of the breathing. The monitoring need is to 
be correlated with patient's pathology when selecting a ventilator for use at the home.

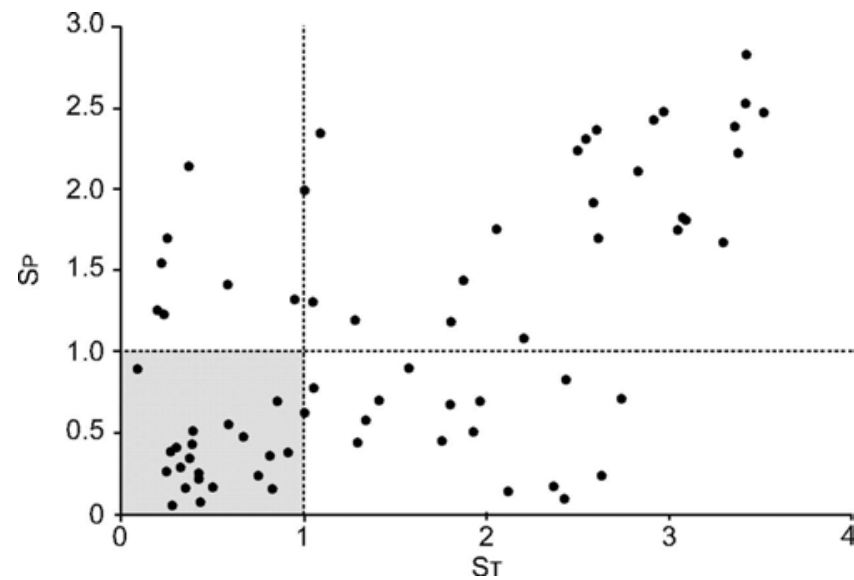

Fig. (6). Graph showing patient-ventilator interactions during NIV. $\mathrm{S}_{\mathrm{T}}$ : Shannon entropy related to ventilatory variability; $\mathrm{S}_{\mathrm{P}}$ : Shannon entropy related to ineffective triggering efforts (optimal zone $S_{P}$ and $\left.\mathrm{S}_{\mathrm{T}}<1\right)$.

Those algorithms and ongoing development have made the Mechnical Ventilators become more technological and potentially more complicated to use. By design, the presence of technology should help the clinician and not overcomplicate the usability of the ventilator. Indeed, lack of ease of use might lead to misunderstanding in ventilation modes and settings and as such create a potential for patient ventilator asynchrony especially when the patient is remote.

In a usability study, J. Gonzales-Bermejo asked 13 ICU physicians to assess the ease of use of 11 home ventilators [51]. When compared with a technical person, the physicians performed poorly yielding the conclusion that userfriendliness of home ventilators might be questionable for physicians not daily using the device.
An additional risk for patient ventilator asynchrony and potential lack of usability, is the lack of common terminology for most of the settings of ventilators. Chatburn proposes a classification system to homogenize the various brand names and ventilation modes although more for the intensive care and sub acute setting [52]. In the home care environment, caregivers will be required to pay extra attention to specific ventilation modes to find the best match between patient and ventilator and ventilator settings.

\section{PITFALLS AND CONSTRAINTS IN THE HOME}

Treatment of ventilation has to be performed on a continuous basis in the home. As shown by Petitjean and colleagues on previously stabilized restrictive patients, withdrawal of NIV leads to first nocturnal respiratory failure and within days diurnal respiratory failure [53]. They recommend not stopping NIV for more than a day or two.

With the advent and cost reduction of memory techniques, most manufacturers of home respiratory support ventilators have implemented systems in the devices to collect a number of information on the use of the device. This information can go from simple usage time up to detailed waveforms of pressure, flow, leakage and cycling.

Farré and colleagues reported in a survey on 300 patients in the Barcelona area [54] that approximately one out of seven ventilators exhibited significant discrepancy (>20\%) between prescribed and actual values (1/20 with a difference of more than $30 \%$ ). In addition the study revealed that when tested, alarms were not working in $0.9 \%$ power-off, $18.6 \%$ disconnection and $5.1 \%$ obstruction for all ventilators. Farré's study enhances the importance of quality control of home mechanical ventilation. So, technology in home ventilation should also prevent settings to be changed from prescribed values.

In a study in the frame of a European Concerted Action on 326 centres and more than 20000 patients, Farré et al.

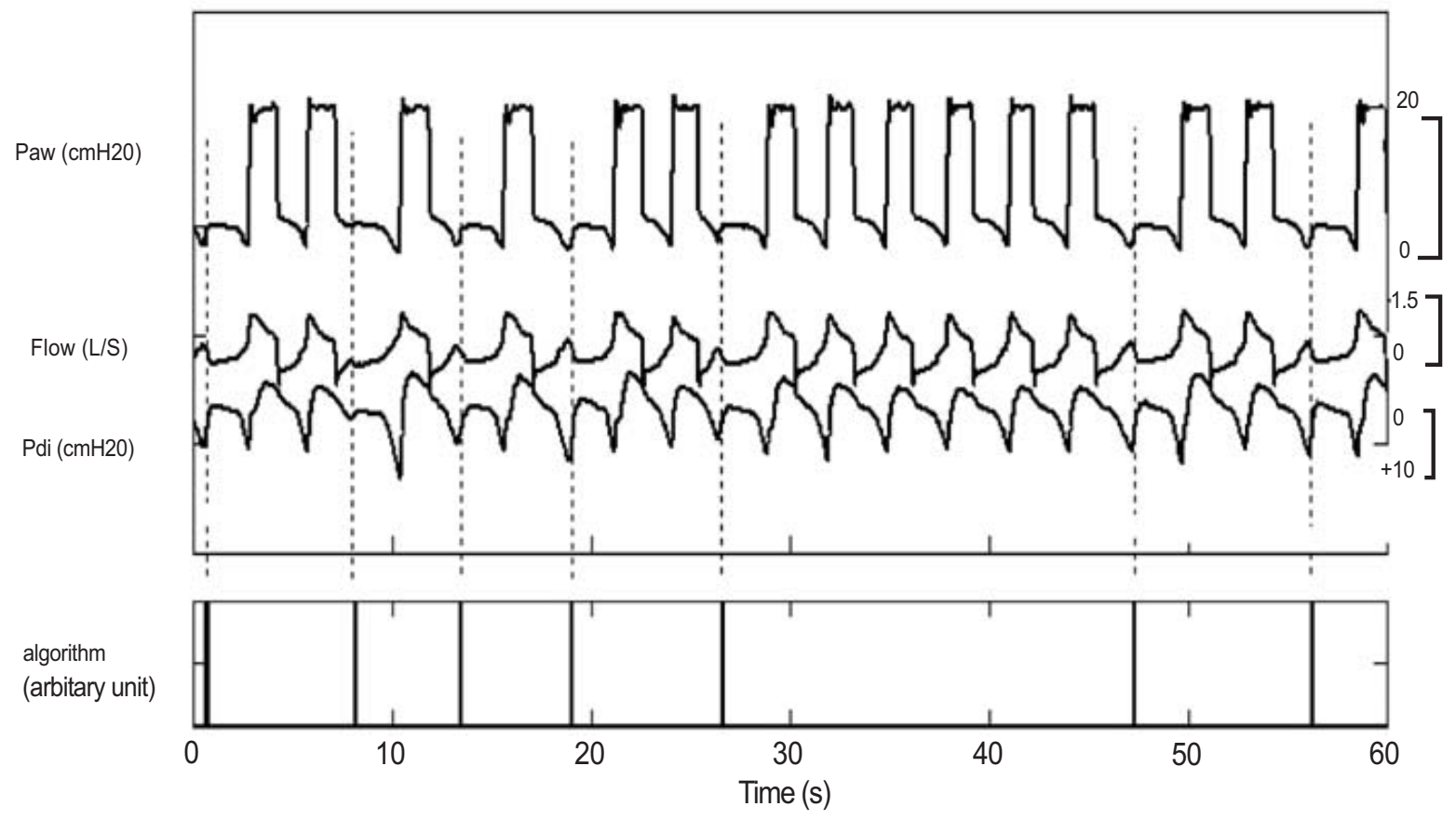

Fig. (7). Traces showing ineffective breaths during PSV [16]. 
showed that servicing of the ventilators is mostly dependant on external companies with significant variance in service interval, service centre size and prescriber feedback information [55]. This variability in service provision might be a reason for some of the discrepancy found previously.

Especially when the patient is at home, monitoring the patient and ventilator quality becomes more difficult even if experiments have been successful [56] using telemedicine. The use of telemedicine is a possible path for both monitoring and performing quality control.
In addition to viewing patient waveforms, readjusting ventilator performance and settings could be possible in the home or in relatively remote settings [50, 57-59]. Many commercial non-medical devices are available to achieve that function (Fig. 8). They could be interfaced with the existing ventilators to build the bridge between home and hospital. This approach has been tested and confirmed on OSA patients $[60,61]$, but not yet on mechanically ventilated patients [62]. One would note that even if telecare has become more present in publications, Botsis and colleagues in a review on Telecare for elderly chronic disease patients
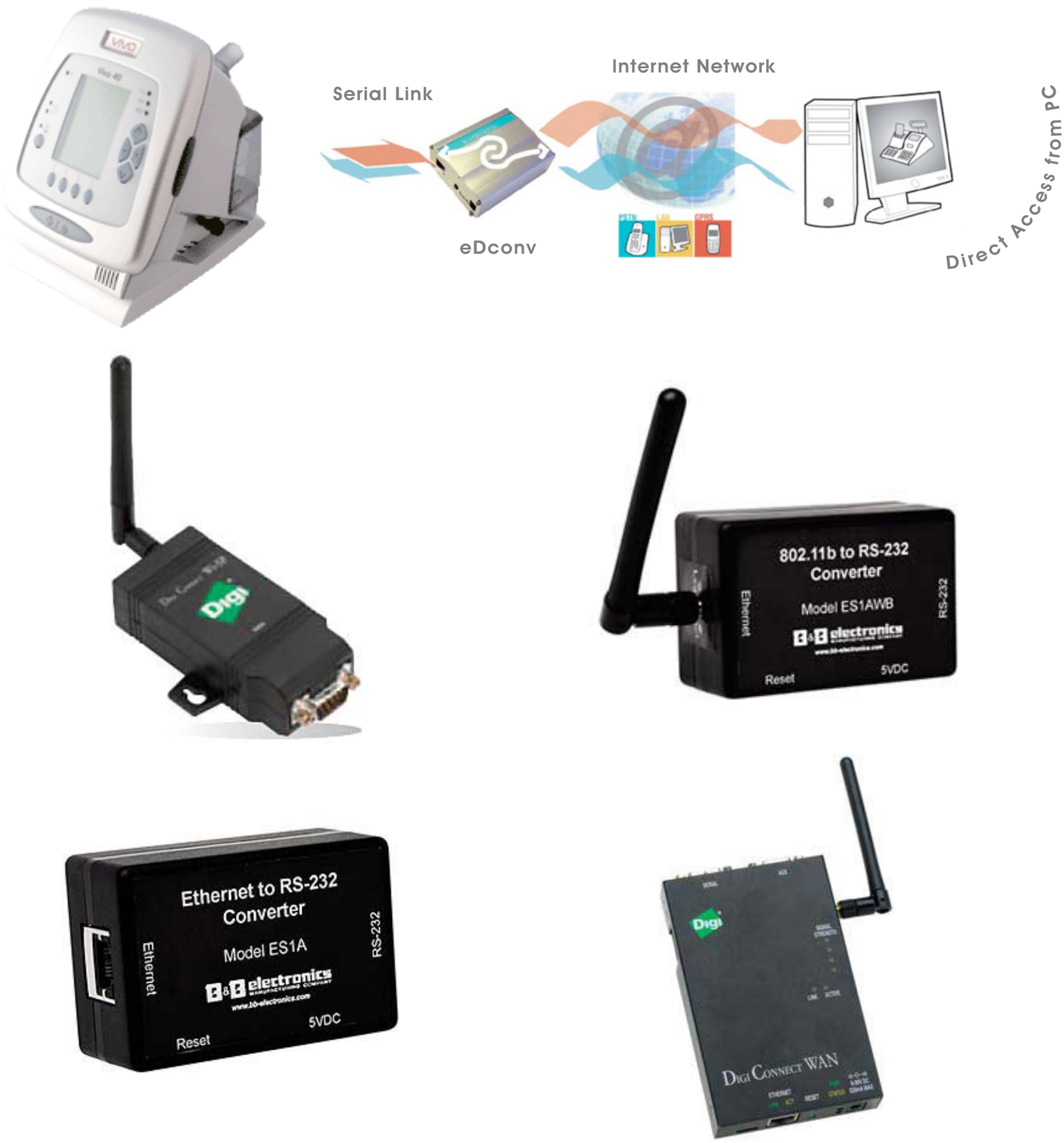

Fig. (8). Various commercially available devices for establishing remote connections. 
revealed that yet less than $10 \%$ of the studies published were on COPD or respiratory related pathologies [63].

Though there are no technical limitations, as the bridges operate via most available carriers (Ethernet, WiFi, GPRS, Bluetooth), the care provider should yet consider additional aspects:

- Financial aspect: the cost of using these add-on devices versus traditional approached

- Legal aspect of telecare: a recent report of the European Commission better outlines the framework [64]

- Liability aspect: modules added to medical devices are considered to be medical devices and should inherently be safe [CE Marking: Medical Device Directive (MDD) - 93/42/EEC].

\section{MANUFACTURER'S INITIATIVES TO MONITOR AND IMPROVE PATIENT-VENTILATOR INTERAC- TION}

Tobin et al. identified four major areas of possible problems in interaction: the triggering of the ventilator, the phase of inspiration after triggering, the passage from inspiration to expiration, and the end of expiration [65].

The same causes were identified by Schönhofer and he proposed corrective actions [66], mostly aimed at inspiratory and expiratory triggers, inspiratory risetime and respiratory rates. This work by Schönhofer leads to investigate various critical components and reasons for failure of putting a ventilator on a patient (Fig. 9). Schönhofer and co-author conclude that, in addition to mask adjustment, adjusting some of the ventilator settings is also a key action to reduce patient ventilator disturbances.

Manufacturers are putting significant effort in designing new techniques for improving triggering and cycling techniques to reduce patient ventilator asynchronies. One should consider that with regards to the financial impact, most companies have elected to take a black-box algorithm hiding intrinsic details for the caregiver. The intellectual property is more commonly disclosed first in patent application before being tested clinically, validated and published.

To assess manufacturer's initiatives, the Intellectual Property was examined on the Wordwide Intellectual Property Office [http: //www.wipo.int/pctdb/en/search-adv.jsp]. In recent years, more than 30 patents have been applied for on various aspects of the asynchrony. Below some of them from various manufacturers:

- $\quad$ Energy Trigger Applicant: BREAS; Publication info: US2008283061

- Method and Apparatus For Detecting Ineffective Inspiratory Efforts and Improving Patient-Ventilator Interaction; Applicant: RESMED; Publication info: US2008110461, based on the work performed by Nava and team [16]

- Determining Suitable Ventilator Settings for Patients with Alveolar Hypoventilation During Sleep; Applicant: RESMED; Publication info: AU2002325399

- Adjustment of Ventilator Pressure-Time Profile to Balance Comfort and Effectiveness; Applicant: RESMED LTD; Publication info: AU2003204620

- Methods and apparatus for varying the back-up rate for a ventilator; Applicant: RESMED LTD; Publication info: NZ541914

- Ventilator patient synchronization; Applicant: RESMED; Publication info: AU2002308423

- Patient-ventilator synchronization using dual phase sensors; Applicant: RESMED; Publication info: EP1810708

- Medical ventilator triggering and cycling method and mechanism; Applicant: RESPIRONICS; Publication info: US2005087190

- Method and device for determining the alveolar ventilation (a.v.) and controlling a respirator; Applicant: WEINMANN; Publication info: EP1985326

- Artificial respiration apparatus adjusting method, involves applying increased volume of respiration gas intermittently with respect to respiration volume for

\begin{tabular}{|c|c|c|}
\hline Problem & Potential cause & Corrective measure \\
\hline \multirow[t]{3}{*}{ Inspiratory trigger failure } & Air leak & Adjust mask or change type \\
\hline & Autocycling & Reduce trigger sensitivity \\
\hline & Increased work of breathing & $\begin{array}{l}\text { Adjust trigger sensitivity or change to } \\
\text { a flow trigger if pressure trigger used }\end{array}$ \\
\hline \multirow[t]{2}{*}{ Inadequate pressurisation } & Pressure rise time too long & Reduction of pressure rise time \\
\hline & Pressure support too low & Increase inspiratory pressure \\
\hline \multirow[t]{2}{*}{$\begin{array}{l}\text { Failure to cycle into } \\
\text { expiration }\end{array}$} & $\begin{array}{l}\text { Air leak leading to "inspriratory } \\
\text { hang up" }\end{array}$ & $\begin{array}{l}\text { Adjust mask or consider switch } \\
\text { from nasal to face mask }\end{array}$ \\
\hline & High end-inspiratory flow & $\begin{array}{l}\text { Increase end-inspiratory flow threshold } \\
\text { and set time limit for inspiration }\end{array}$ \\
\hline \multirow[t]{4}{*}{$\mathrm{CO}_{2}$ rebreathing } & $\begin{array}{l}\text { Single circuit with no true } \\
\text { exhalation valve }\end{array}$ & Use two lines and use nonrebreathe valve \\
\hline & High respiratory rate & Lower respiratory rate \\
\hline & No PEEP & Add PEEP to lavage mask \\
\hline & Large mask dead space & Reduce dead space with padding \\
\hline
\end{tabular}

$\mathrm{CO}_{2}$ : carbon dioxide; PEEP: positive end-expiratory pressure.

Fig. (9). Troubleshooting of crucial issues in pressure support ventilation [67]. 


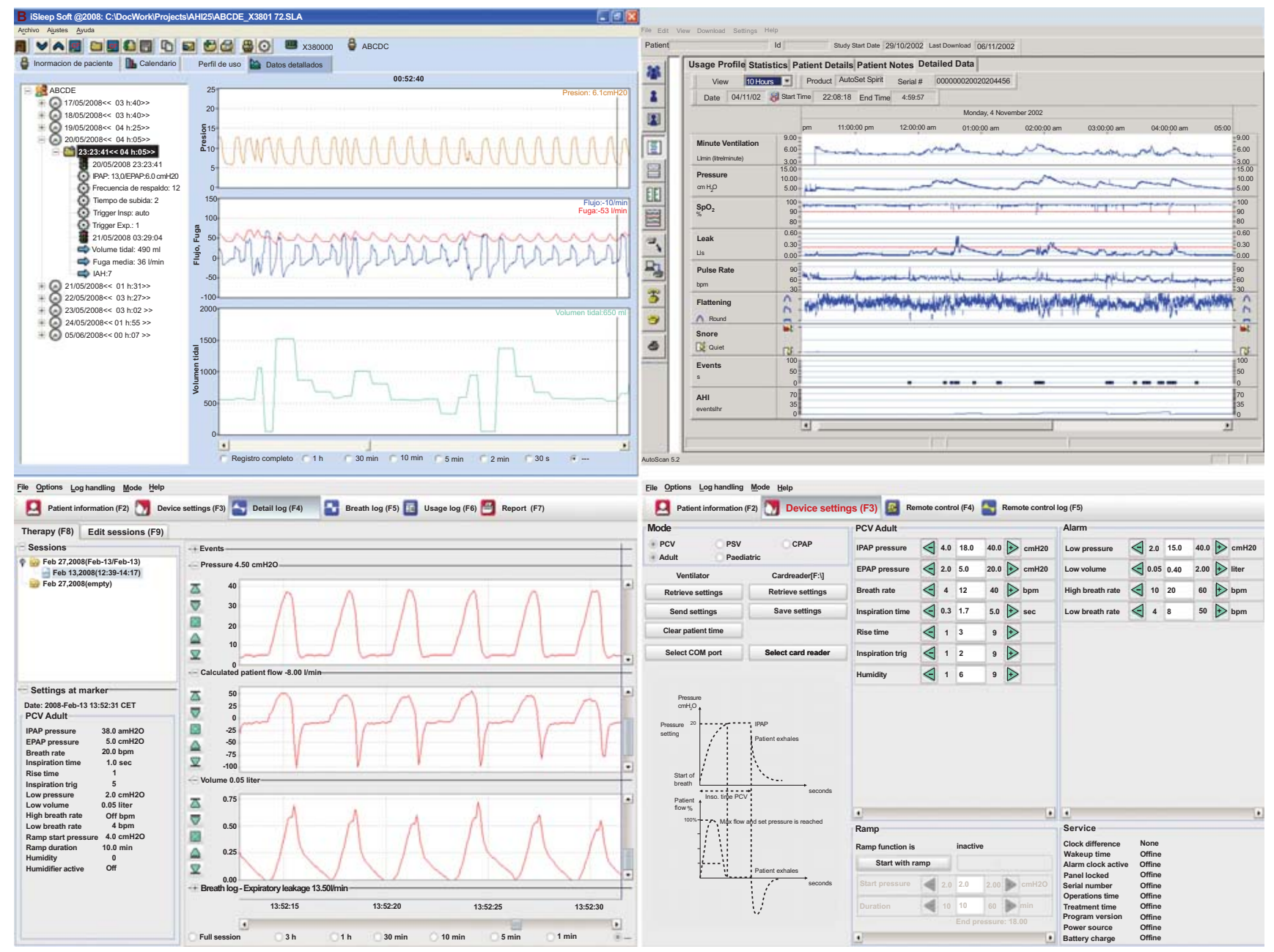

Fig. (10). Screenshots of 3 commercially available software packages to log patient/ventilator interaction or change settings online or remotely.

assisted respiration, and realizing deep insufflations by adjustment of pressure; Applicant: WEINMANN; Publication info: DE102007033048

- $\quad$ Method and device for controlling a ventilator; Applicant: WEINMANN; Publication info: DE102007011 924

Although these patent applications are in process, they will not per se be integrated in actual ventilators, as patents are also ways of avoiding competition on one's unique technique.

Manufacturers yet make other treatment oriented information available for the clinician and the caregiver. The availability of this information opens new paths for documenting the therapy and tracking how the patient is using his breathing assistance device. This memory logging of events discloses the entire therapy without the additional costs linked of in-hospital or ambulatory monitoring (Fig. 10).

\section{CONCLUSION}

With the advent of reduced and more powerful electronics, medical equipment in general and non-invasive respiratory support devices in particular have been increasingly made available for the patient in his home environment.
Although beneficial for the patient, this prevents the clinician to have direct control on the patient. Commercially available device relying on various communication techniques now technically give the possibility to remotely monitor the patient in his own familiar environment. The legal and financial framework around this telemedicine is however not entirely ready yet.

Progress in technologies also led to an improved handling of patient-device interaction. Indeed, especially in unsupervised non-invasive ventilation, patient ventilator asynchronies are common. As part of an ongoing effort for better patient-ventilator matching, manufacturers are promoting new or improved ventilation modes. Even though these ventilation modes have become more responsive to patient efforts, adversely they might lead to events such as false triggering, auto-triggering, delayed triggering. Developments for an improved clinician's feedback on asynchrony and adjusting the ventilator are ongoing.

Finally, in order to track patient/ventilator interaction and usage, manufacturers have embedded memory in most modern respiratory devices. This logging is beneficial for the caregiver to a posteriori analyze the treatment and tune the settings to the patient's need and comfort. 
To conclude there is a need for a joint effort of manufacturers and caregivers (clinicians, service centres) to assure that the patient ventilator interaction is optimized to ensure best treatment.

\section{REFERENCES}

[1] Esteban A, Anzueto A, Alia I, et al. How is mechanical ventilation employed in the intensive care unit? An international utilization review. Am J Respir Crit Care Med 2000; 161: 1450-8.

[2] Frutos F, Alia I, Esteban A, Anzueto A. Evolution in the utilization of the mechanical ventilation in the critical care unit. Minerva Anestesiol 2001; 67: 215-22.

[3] Esteban A, Ferguson ND, Meade MO, et al. Evolution of mechanical ventilation in response to clinical research. Am J Respir Crit Care Med 2008; 15; 177: 170-7.

[4] Crimi C, Noto A, Esquinas A, Nava S. Non-invasive ventilation (NIV) practices: a European web-survey. ERJ 2008 ERS Proceedings, p. 337s.

[5] Corrado A, Roussos C, Ambrosino N, et al. Respiratory intermediate care units: a European survey. Eur Respir J 2002; 20: 1343-50.

[6] Muir JF, Cuvelier A. Instrumental management of chronic respiratory insufficiency: contribution of long-term therapeutic assistance at home. Bull Acad Natl Med 1998; 182: 1139-56.

[7] Fauroux B, Howard P, Muir JF. Home treatment for chronic respiratory insufficiency: the situation in Europe in 1992. The European Working Group on Home Treatment for Chronic Respiratory Insufficiency. Eur Respir J 1994; 7: 1721-6.

[8] Lloyd-Owen SJ, Donaldson GC, Ambrosino N, et al. Patterns of home mechanical ventilation use in Europe: results from the Eurovent survey. Eur Respir J 2005; 25: 1025-31.

[9] Janssens JP, Derivaz S, Breitenstein E, et al. Changing patterns in long-term noninvasive ventilation: a 7-year prospective study in the Geneva Lake area. Chest 200; 123: 67-79.

[10] Antonelli M, Conti G, Pennisi MA, Arcangeli A, Proietti R. Home mechanical ventilation: the extra-hospital phase. Minerva Anestesiol 2000; 66: 895-9.

[11] Clini E, Vitacca M, Foglio K, Simoni P, Ambrosino N. Long-term home care programmes may reduce hospital admissions in COPD with chronic hypercapnia. Eur Respir J 1996; 9: 1605-10.

[12] Clini EM, Magni G, Crisafulli E, Viaggi S, Ambrosino N. Home non-invasive mechanical ventilation and long-term oxygen therapy in stable hypercapnic chronic obstructive pulmonary disease patients: comparison of costs. Respiration 2009; 77: 44-50.

[13] Tuggey JM, Plant PK, Elliott MW. Domiciliary non-invasive ventilation for recurrent acidotic exacerbations of COPD: an economic analysis. Thorax 2003; 58: 867-71.

[14] Guo YF, Sforza E, Janssens JP. Respiratory patterns during sleep in obesity-hypoventilation patients treated with nocturnal pressure support: a preliminary report. Chest 2007; 131: 1090-9.

[15] Thille AW, Rodriguez P, Cabello B, Lellouche F, Brochard L. Patient-ventilator asynchrony during assisted mechanical ventilation. Intensive Care Med 2006; 32: 1515-22.

[16] Mulqueeny Q, Ceriana P, Carlucci A, Fanfulla F, Delmastro M, Nava S. Automatic detection of ineffective triggering and double triggering during mechanical ventilation. Intensive Care Med 2007; 33: 2014-8.

[17] Cao ZX, Wang C. The effects of auto-triggering on patientventilator interaction in noninvasive mechanical ventilation during air leak. Zhonghua Jie He He Hu Xi Za Zhi 2008; 31: 116-9.

[18] Miyoshi E, Fujino Y, Uchiyama A, Mashimo T, Nishimura M. Effects of gas leak on triggering function, humidification, and inspiratory oxygen fraction during noninvasive positive airway pressure ventilation. Chest 2005; 128: 3691-8.

[19] Puy MC, Samolski D, Sotomayor C, Madariaga G, Guell MR, Anton PA. Relationship between air leaks and efectivity of noninvasive ventilation. a pilot study. ERJ 2007, ERS Proceedings, ERS p. $721 \mathrm{~s}$.

[20] Borel JC, Sabil AK, Janssens JP, et al. Intentional leaks in industrial masks have a significant impact on efficacy of bilevel noninvasive ventilation: a bench test study. Chest 2008; [Epub ahead of print].

[21] Tuggey JM, Delmastro M, Elliott MW. The effect of mouth leak and humidification during nasal non-invasive ventilation. Respir Med 2007; 101: 1874-9.
[22] Schettino GP, Tucci MR, Sousa R, Valente Barbas CS, Passos Amato MB, Carvalho CR. Mask mechanics and leak dynamics during noninvasive pressure support ventilation: a bench study. Intensive Care Med 2001; 27: 1887-91.

[23] Vignaux L, Vargas F, Roeseler J, et al. Patient-ventilator asynchrony during non-invasive ventilation for acute respiratory failure: a multicenter study. Intensive Care Med 2009; [Epub ahead of print].

[24] Willson GN, Piper AJ, Norman M, et al. Nasal versus full face mask for noninvasive ventilation in chronic respiratory failure. Eur Respir J 2004; 23: 605-9.

[25] Meyer TJ, Pressman MR, Benditt J, et al. Air leaking through the mouth during nocturnal nasal ventilation: effect on sleep quality. Sleep 1997; 20: 561-9.

[26] Fanfulla F, Taurino AE, Lupo ND, Trentin R, D'Ambrosio C, Nava S. Effect of sleep on patient/ventilator asynchrony in patients undergoing chronic non-invasive mechanical ventilation. Respir Med 2007; 101: 1702-7.

[27] Fanfulla F, Delmastro M, Berardinelli A, Lupo ND, Nava S. Effects of different ventilator settings on sleep and inspiratory effort in patients with neuromuscular disease. Am J Respir Crit Care Med 2005; 172: 619-24.

[28] Fauroux B, Leroux K, Desmarais G, et al. Performance of ventilators for noninvasive positive-pressure ventilation in children. Eur Respir J 2008 31: 1300-7.

[29] Ferreira JC, Chipman DW, Kacmarek RM. Trigger performance of mid-level ICU mechanical ventilators during assisted ventilation: a bench study. Intensive Care Med 2008; 34: 1669-75.

[30] Vignaux L, Tassaux D, Jolliet P. Performance of noninvasive ventilation modes on ICU ventilators during pressure support: a bench model study. Intensive Care Med 2007; 33: 1444-51.

[31] Battisti A, Tassaux D, Janssens JP, Michotte JB, Jaber S, Jolliet P. Performance characteristics of 10 home mechanical ventilators in pressure-support mode: a comparative bench study. Chest 2005; 127: 1784-92.

[32] Tassaux D, Strasser S, Fonseca S, Dalmas E, Jolliet P. Comparative bench study of triggering, pressurization, and cycling between the home ventilator VPAP II and three ICU ventilators. Intensive Care Med 2002; 28: 1254-61.

[33] Richard JC, Carlucci A, Breton L, et al. Bench testing of pressure support ventilation with three different generations of ventilators. Intensive Care Med 2002; 28: 1049-57.

[34] Smith IE, Shneerson JM. A laboratory comparison of four positive pressure ventilators used in the home. Eur Respir J 1996; 9: 2410-5.

[35] Stell IM, Paul G, Lee KC, Ponte J, Moxham J. Noninvasive ventilator triggering in chronic obstructive pulmonary disease: a test lung comparison. Am J Respir Crit Care Med 2001; 164: 2092-7.

[36] Chatburn RL. Which ventilators and modes can be used to deliver noninvasive ventilation? Respir Care 2009; 54: 85-101.

[37] Highcock MP, Morrish E, Jamieson S, Shneerson JM, Smith IE. An overnight comparison of two ventilators used in the treatment of chronic respiratory failure. Eur Respir J 2002 ; 20: 942-5.

[38] Stroetz RW, Hubmayr RD. Patient-ventilator interactions. Monaldi Arch Chest Dis 1998; 53: 331-6.

[39] Haynes JM. Patient-ventilator asynchrony in a sleeping patient receiving pressure-support ventilation. Respir Care 2008; 53: 10858.

[40] Georgopoulos D, Prinianakis G, Kondili E. Bedside waveforms interpretation as a tool to identify patient-ventilator asynchronies. Intensive Care Med 2006; 32: 34-47.

[41] Kallet RH, Luce JM. Detection of patient-ventilator asynchrony during low tidal volume ventilation, using ventilator waveform graphics. Respir Care 2002; 47: 183-5.

[42] Dhand R. Ventilator graphics and respiratory mechanics in the patient with obstructive lung disease. Respir Care 2005; 50: 24661.

[43] Nilsestuen JO, Hargett KD. Using ventilator graphics to identify patient-ventilator asynchrony. Respir Care 2005; 50: 202-34.

[44] Chen CW, Lin WC, Hsu CH, Cheng KS, Lo CS. Detecting ineffective triggering in the expiratory phase in mechanically ventilated patients based on airway flow and pressure deflection: feasibility of using a computer algorithm. Crit Care Med 2008; 36: 455-61.

[45] Battisti A, Tassaux D, Bassin D, Jolliet P. Automatic adjustment of noninvasive pressure support with a bilevel home ventilator in patients with acute respiratory failure: a feasibility study. Intensive Care Med 2007; 33: 632-8. 
[46] Battisti A, Roeseler J, Tassaux D, Jolliet P. Automatic adjustment of pressure support by a computer-driven knowledge-based system during noninvasive ventilation: a feasibility study. Intensive Care Med 2006; 32: 1523-8.

[47] Achour L, Letellier C, Cuvelier A, Verin E, Muir JF. Asynchrony and cyclic variability in pressure support noninvasive ventilation. Comput Biol Med 2007; 37: 1308-20.

[48] Letellier C, Rabarimanantsoa H, Achour L, Cuvelier A, Muir JF. Recurrence plots for dynamical analysis of non-invasive mechanical ventilation. Philos Transact A Math Phys Eng Sci 2008; 366: 621-34.

[49] Rabarimanantsoa H, Achour L, Letellier C, Cuvelier A, Muir JF. Recurrence plots and Shannon entropy for a dynamical analysis of asynchronisms in noninvasive mechanical ventilation. Chaos 2007; 17: 013115.

[50] Vitacca M, Guerra A, Assoni G, et al. Weaning from mechanical ventilation followed at home with the aid of a telemedicine program. Telemed J E Health 2007; 13: 445-9.

[51] Gonzalez-Bermejo J, Laplanche V, Husseini FE, Duguet A, Derenne JP, Similowski T. Evaluation of the user-friendliness of 11 home mechanical ventilators. Eur Respir J 2006; 27: 1236-43.

[52] Chatburn RL. Classification of ventilator modes: update and proposal for implementation. Respir Care 2007; 52(3): 301-23

[53] Petitjean T, Philit F, Germain-Pastenne M, Langevin B, Guerin C. Sleep and respiratory function after withdrawal of noninvasive ventilation in patients with chronic respiratory failure. Respir Care 2008; 53: 1316-23.

[54] Farre R, Navajas D, Prats E, et al. Performance of mechanical ventilators at the patient's home: a multicentre quality control study. Thorax 2006; 61: 400-4.

[55] Farre R, Lloyd-Owen SJ, Ambrosino N, et al. Quality control of equipment in home mechanical ventilation: a European survey. Eur Respir J 2005; 26: 86-94.
[56] Lujan M, Moreno A, Veigas C, Monton C, Pomares X, Domingo C. Non-invasive home mechanical ventilation: effectiveness and efficiency of an outpatient initiation protocol compared with the standard in-hospital model. Respir Med 2007; 101: 1177-82.

[57] Johannigman J, Branson RD, Muskat P, Barnes SL, Beck G. Closed loop control of oxgenation and ventilation. J Gravit Physiol 2007; 14: 35-8.

[58] Howard WR. Wireless on-demand and networking of Puritan Bennett 840 ventilators for direct data capture. Respir Care 2007; 52: $1530-41$

[59] Tura A, Santini P, Longo D, Quareni L. A telemedicine instrument for home monitoring of patients with chronic respiratory diseases. Ann Ist Super Sanita 2007; 43: 101-9.

[60] Dellaca R, Govoni L, Montserrat JM, Farre R, Mayos M, Pedotti A. Titration of home CPAP in obstructive sleep apneas syndrome (OSAS) through real time telemetry. ERJ 2008 ERS Proceedings, p. $119 \mathrm{~s}$.

[61] Stepnowsky CJ, Palau JJ, Marler MR, Gifford AL. Pilot randomized trial of the effect of wireless telemonitoring on compliance and treatment efficacy in obstructive sleep apnea. J Med Internet Res 2007; 9: e14.

[62] Dellaca R, Govoni L, Navajas D, Farre R, Pedotti A. A novel simple internet-based system for real time monitoring and optimizing home mechanical ventilation. ERJ 2008, ERS Proceedings, p. 334s.

[63] Botsis T, Hartvigsen G. Current status and future perspectives in telecare for elderly people suffering from chronic diseases. J Telemed Telecare 2008; 14: 195-203.

[64] European Commission. Legally eHealth: putting eHealth in its European Legal Context. European Commission 2008.

[65] Tobin MJ, Jubran A, Laghi F. Patient-ventilator interaction. Am J Respir Crit Care Med 2001; 163: 1059-63.

[66] Schonhofer B, Sortor-Leger S. Equipment needs for noninvasive mechanical ventilation. Eur Respir J 2002; 20: 1029-36.

(C) Evers and Loey; Licensee Bentham Open.

This is an open access article licensed under the terms of the Creative Commons Attribution Non-Commercial License (http://creativecommons.org/licenses/by$\mathrm{nc} / 3.0 /$ ) which permits unrestricted, non-commercial use, distribution and reproduction in any medium, provided the work is properly cited. 